\title{
Reintervention after endovascular repair for aortic dissection: A systematic review and meta-analysis
}

\author{
Lei Zhang, MD, ${ }^{\mathrm{a}}$ Zhiqing Zhao, MD, ${ }^{\mathrm{b}}$ Yanqing Chen, MM, ${ }^{\mathrm{a}}$ Yudong Sun, MD, ${ }^{\mathrm{a}}$ Junmin Bao, MD, ${ }^{\mathrm{a}}$
}

Zaiping Jing, $\mathrm{MD}, \mathrm{PhD},{ }^{\mathrm{a}}$ and Jian Zhou, MD

\section{ABSTRACT}

Objectives: Thoracic endovascular aortic repair has been chosen as a lessinvasive alternative to open surgery for the treatment of aortic dissections; however, the advantages have been challenged by the postoperative reintervention during the follow-up period. This study aimed at evaluating the incidence, reasons, and potential risk factors for reintervention.

Methods: Studies reporting reintervention after endovascular repair were identified by searching PubMed and Embase in accordance with preferred reporting items for systematic reviews and meta-analyses guidelines, and by reviewing the reference lists of retrieved articles. Sensitivity analysis and subgroup analyses were performed to determine the sources of heterogeneity. Funnel plot and Egger's test were used to determine the publication bias.

Results: A total of 27 studies encompassing 2403 patients with aortic dissection were identified. The pooled incidence of reintervention after endovascular repair was $15 \%$ (95\% confidence interval, 12-19) during 33.7 months of follow-up. The 3 most common reasons for reintervention were endoleak (33.2\%), false lumen perfusion and aortic dilation (19.8\%), and new dissection (6.9\%). The potential factors for reintervention were the mean age of onset and diabetes mellitus determined by performing a single meta-regression analysis $(P<.001$ and .044 , respectively).

Conclusions: Current data suggest that the incidence of reintervention after endovascular therapy is relatively high during midterm follow-up. Advanced age of onset is a risk factor and diabetes mellitus is a protective factor of reintervention after endovascular therapy. The possible mechanism that diabetes mellitus protects patients from reintervention should be explored further. (J Thorac Cardiovasc Surg 2016;152:1279-88)

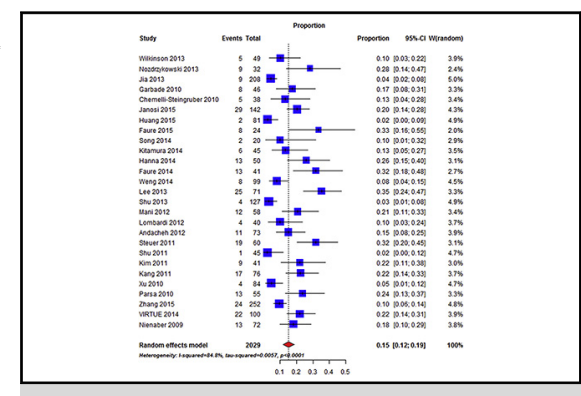

The overall incidence of reintervention after TEVAR.

\section{Central Message}

The pooled estimated incidence of reintervention after endovascular repair was $15 \%$, and the 3 most common reasons were endoleak, false lumen perfusion and aortic dilation, and new dissection.

\section{Perspective}

The incidence of reintervention after endovascular repair was relatively high during midterm follow-up. For patients with aortic dissection with an advanced age of onset, more elaborate operation and close postoperative care are required to lower the reintervention rate and improve the prognosis of aortic dissection.

See Editorial Commentary page 1289.
The estimated annual incidence of aortic dissection is 2 to 6 per 100,000 individuals, and the prevalence appears to be increasing independently of the aging population. ${ }^{1}$ The advent of thoracic endovascular aortic repair (TEVAR)

\footnotetext{
From the Departments of a Vascular Surgery and ${ }^{\mathrm{b}}$ Surgery, Changhai Hospital, Second Military Medical University, Shanghai, China.

This study was supported by grants from the National Natural Science Foundation of China (Nos. 81330034, 81273522, and 81170299). The funders had no role in the study design, data collection and analysis, writing of the manuscript, and decision to submit the article for publication.

Received for publication Feb 5, 2016; revisions received June 1, 2016; accepted for publication June 17, 2016; available ahead of print July 21, 2016

Address for reprints: Zaiping Jing, MD, PhD, Department of Vascular Surgery, Changhai Hospital, 168 Changhai Rd, Yangpu District, Shanghai 200433, China (E-mail: xueguanky@163.com).

$0022-5223 / \$ 36.00$

Copyright (C) 2016 by The American Association for Thoracic Surgery

http://dx.doi.org/10.1016/j.jtcvs.2016.06.027
}

has altered the management algorithm for aortic dissections. ${ }^{2}$ Because TEVAR is associated with lower risks of mortality and morbidity, the procedure has been chosen as a less-invasive alternative to traditional open surgery for the treatment of complicated type B aortic dissections in recent years, especially in elderly patients with greater comorbidities. ${ }^{3,4}$ However, the advantages of TEVAR have been challenged by the postoperative adverse events, such as endoleak, stent-graft migration, retrograde type A aortic dissection (RTAD), and distal redissection. In most

Scanning this QR code will take you to a video, supplemental figures, and tables, for the article.

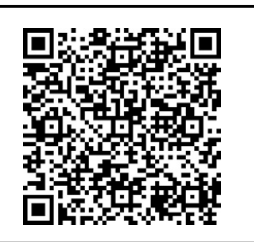




\section{Abbreviations and Acronyms}

$\mathrm{CI}=$ confidence interval

RTAD = retrograde type A aortic dissection

TEVAR $=$ thoracic endovascular aortic repair

situations, these events require reintervention to save lives or obtain a better prognosis. It is conceivable that the prognosis of TEVAR could be improved after determining the reasons and potential risk factors of reintervention. To date, nonetheless, no systematic review and meta-analysis of reintervention after TEVAR for aortic dissections have been performed.

In the current study, we systematically reviewed all available published data reporting reintervention after TEVAR in patients with aortic dissection and pooled the data for analyzing the incidence, reasons, and potential risk factors for reintervention.

\section{MATERIALS AND METHODS}

This systematic review and meta-analysis were performed in accordance with the standards set forth by the statement from the Preferred Reporting Items for Systematic Reviews and Meta-Analyses. ${ }^{5}$ Because this study was a systematic review and meta-analysis based on published articles, ethical approval was waived by the Institutional Review Board of Changhai Hospital. Video 1 shows the topic selection process of reintervention after endovascular therapy.

\section{Data Sources and Search Results}

The PubMed and Embase databases were searched from inception to June 2, 2015, restricted to studies in English and on humans. There were no restrictions on the year or type of publication. The search strategy was amended for each database (Table E1). A hand search also was performed of all the references in the included studies for potential valuable and relevant publications.

\section{Study Selection}

The inclusion criteria were (1) patients with aortic dissection requiring another intervention after TEVAR, (2) at least 10 patients in the study, and (3) at least 6 months of follow-up. On the basis of the guidelines, case reports, conference abstracts, reviews, systematic review, and meta-analyses, other researches and other diseases were excluded. After full-text articles were assessed for eligibility, the mixed pathology including both aortic dissections and aneurysms was excluded.

\section{Data Extraction and Outcome Definitions}

Two investigators independently assessed studies for inclusion criteria and extracted data using a standard form. Disagreements were resolved by consensus with internal authors at designated consensus meetings. Data were extracted pertaining to the baseline demographics, comorbidities, follow-up period, study design, years of enrollment, incidence and reasons for reintervention, prior aortic intervention rate, technical success rate, in-hospital/30-day mortality, and oversizing of the stent graft.

The outcomes were the incidence, reasons, and potential factors for reintervention after TEVAR during follow-up. Reintervention was defined as the second intervention for the management of complications after the initial TEVAR, not including the second-stage operation. Potential risk factors were defined as the factors for reintervention determined by single meta-

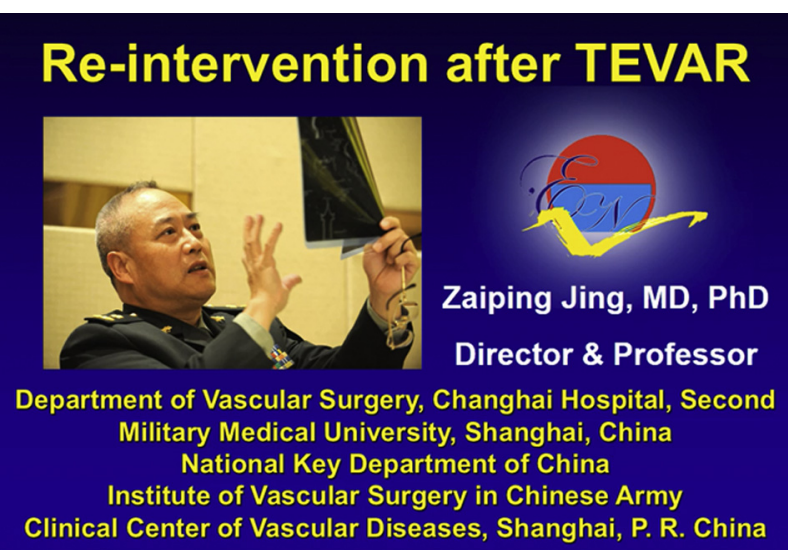

VIDEO 1. How did we choose the topic of reintervention after endovascular therapy? Video available at: http://www.jtcvsonline.org/article/S00225223(16)30657-2/addons.

regression analyses on the variables of age, male gender, follow-up period, technical success, in-hospital/30-day mortality, prior aortic intervention, Marfan syndrome, and comorbidities. Type I endoleak was defined as a sealing failure at 1 of the attachment sites of the graft to the vessel wall (proximal leak, type Ia; distal, type Ib), whereas type III endoleak was defined as a device failure in the form of dysjunction of the components of a modular graft system (type IIIa) or a defect in the fabric of the graft (type IIIb). New dissection referred to the new-onset and metachronous dissection separate from the initially treated aortic dissection, which precluded the RTAD or stent graft-induced dissection. Persistent perfusion of the false lumen meant the blood flow persistently entered into the false lumen through the distal reentry tears, which resulted in aortic dilation or rupture.

\section{Data Synthesis and Statistical Analysis}

The amount of heterogeneity was estimated using $\mathrm{I}^{2}$ statistics, which indicates the percent of heterogeneity across studies that cannot be explained by chance variation alone. $\mathrm{I}^{2}$ greater than $50 \%$ was considered to indicate high heterogeneity. Sensitivity analysis was performed, and a randomeffect model was chosen when heterogeneity was greater than 50\%. Publication bias was assessed through a funnel plot, and Egger's regression test was applied.

The values were expressed as numbers, percentages, and median $/ \mathrm{mean}$. Potential factors for reintervention were determined by a single metaregression analysis using STATA version 12.0 (StataCorp LP, College Station, Tex). The pooled estimated incidence of reintervention after TEVAR was performed using R-project (version 3.2.0, http://www.r-project.org/). The probability values were 2 tailed, and the null hypothesis was rejected for $P$ values less than .05 .

\section{RESULTS \\ Study Selection and Characteristics}

The literature search identified 293 potentially relevant studies, as shown in the flow diagram in Figure 1. Of these, 29 full-text articles were assessed for eligibility. Finally, 27 studies comprising 2403 patients with aortic dissection (2029 TEVAR, 44 open surgery, and 330 medication cases) between 1995 and April 2013 were included in the metaanalysis. ${ }^{3,6-31}$

The patients' characteristics and comorbidities are summarized in Table 1. Almost all of the patients were 


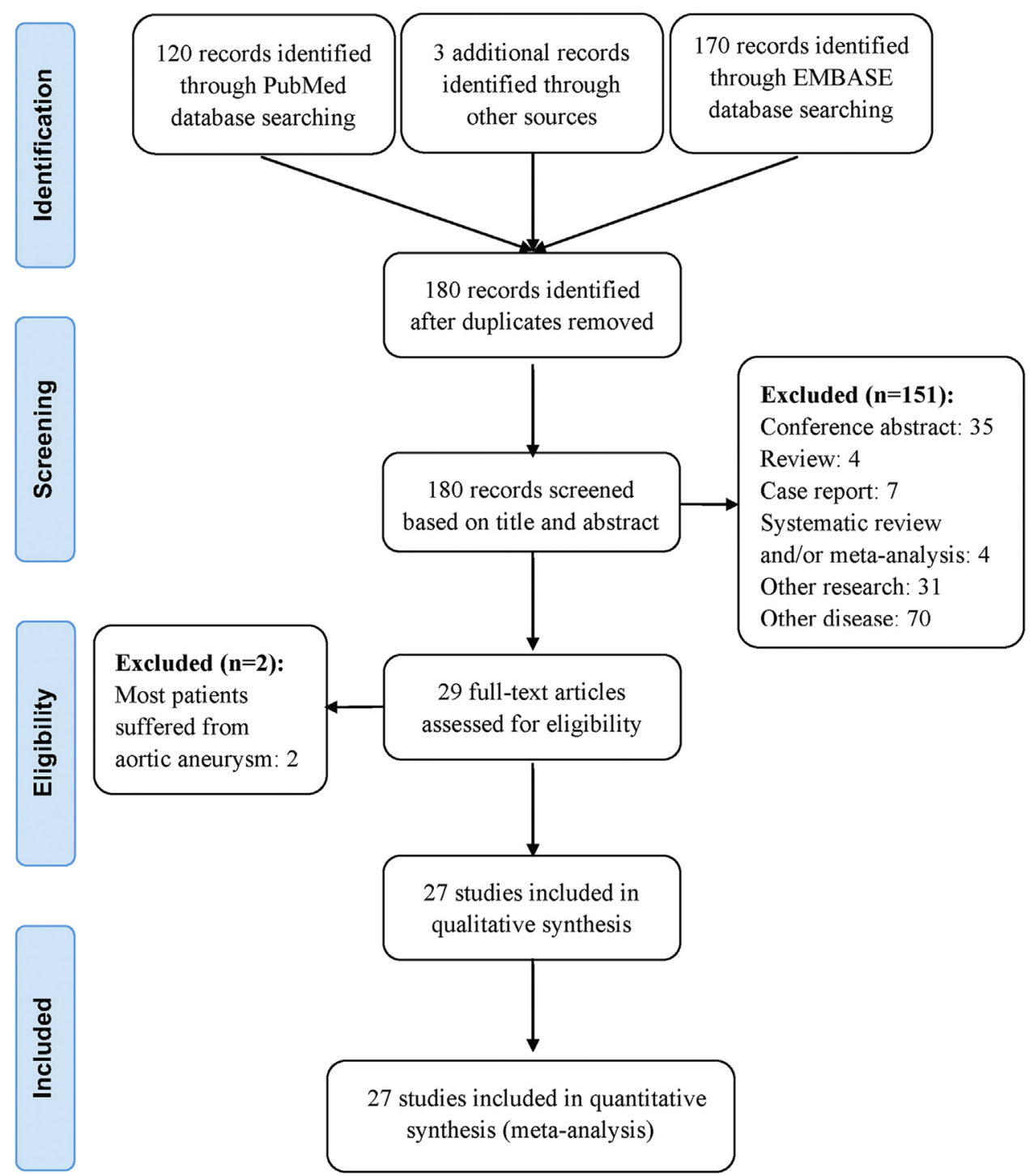

FIGURE 1. Flow diagram according to the Preferred Reporting Items for Systematic Reviews and Meta-Analyses guidelines.

diagnosed with type B aortic dissections. The average age was 57.6 years, and $75.7 \%$ of patients were men. The comorbidities were coronary artery disease $(14.0 \%)$, chronic obstructive pulmonary disease $(12.7 \%)$, diabetes mellitus $(8.8 \%)$, hypertension $(80.9 \%)$, renal insufficiency $(12.3 \%)$, and smoking $(50.0 \%)$. The percentage of patients diagnosed with Marfan syndrome was $2.2 \%$.

\section{Incidence, Reasons, and Potential Risk Factors for Reintervention}

The perioperative characteristics and incidence of reintervention of included studies are presented in Table 2. The pooled estimates of prior aortic intervention rate, technical success, and in-hospital/30-day mortality were $15.0 \%, 98.3 \%$, and $4.3 \%$, respectively. Mean follow-up period was 33.7 months.
The incidence of reintervention after TEVAR is depicted in Figure 2. The pooled overall incidence of reintervention was $15 \%(95 \%$ confidence interval $[\mathrm{CI}], 12-19)$ with a large degree of heterogeneity $\left(\mathrm{I}^{2}=84.8 \%\right)$. A funnel plot is presented in Figure E1 (Egger's regression test, $P<.001)$.

To determine the potential sources of heterogeneity, a sensitivity analysis of included studies using a random effect model was performed (Table E2). However, the heterogeneity was still high after omitting each one of the studies. Then, the subgroup analyses of reported acute, $^{3,9,10,12,13,19,23-25} \quad$ chronic, ${ }^{7,8,14,18,20,22,26,27,31}$ complicated, $3,6,13,14,16,18,21-26,28-30$ and prior aortic intervention $3,6,7,11,13,15,16,18,20,21,26,28$ dissections were performed. The pooled incidences of reintervention in acute and chronic dissection subgroups were 14\% (95\% 
TABLE 1. Baseline characteristics of included study subjects

\begin{tabular}{|c|c|c|c|c|c|}
\hline Study reference and year & Time span & Design & Disease & Patients, n & Mean age, $\mathbf{y}$ \\
\hline Wilkinson and colleagues $^{6} 2013$ & $1995-2012$ & Retrospective, single center & Complicated TBAD & 49 & 70.1 \\
\hline Nozdrzykowski and colleagues ${ }^{7} 2013$ & $1 / 2000-5 / 2010$ & Retrospective, single center & CTBAD & 32 & 62.0 \\
\hline Jia and colleagues ${ }^{8} 2013$ & $1 / 2007-12 / 2010$ & Prospective, multicenter & Uncomplicated CTBAD & 208 & 52.1 \\
\hline Garbade and colleagues $^{9} 2010$ & 2000-2008 & Retrospective, single center & ATBAD & 46 & 65.0 \\
\hline Chemelli-Steingruber and colleagues ${ }^{10} 2010$ & $7 / 1996-4 / 2008$ & Retrospective, single center & ATBAD & 38 & 64.0 \\
\hline Jánosi and colleagues ${ }^{11} 2015$ & $7 / 1999-5 / 2010$ & Retrospective, single center & TBAD & 142 & 62.2 \\
\hline Huang and colleagues ${ }^{12} 2015$ & $1 / 2012-6 / 2012$ & Retrospective, single center & ATBAD & 81 & 53.0 \\
\hline Faure and colleagues ${ }^{13} 2015$ & 2000-2013 & Retrospective, 2 centers & Complicated ATBAD & 24 & 68.0 \\
\hline Song and colleagues ${ }^{14} 2014$ & $5 / 2012-4 / 2013$ & Retrospective, single center & Complicated CTBAD & 20 & 50.0 \\
\hline Kitamura and colleagues ${ }^{15} 2014$ & $1998-2012$ & Retrospective, single center & TBAD & 45 & 55.5 \\
\hline Hanna and colleagues ${ }^{3} 2014$ & $7 / 2005-9 / 2012$ & Retrospective, single center & Complicated ATBAD & 50 & $59.0 *$ \\
\hline Faure and colleagues ${ }^{16} 2014$ & $10 / 2000-12 / 2011$ & Retrospective, single center & Complicated AD & 41 & 66.0 \\
\hline Weng and colleagues ${ }^{17} 2013$ & $11 / 2006-5 / 2011$ & Retrospective, single center & $\mathrm{AD}$ & 99 & 60.0 \\
\hline Lee and colleagues ${ }^{18} 2013$ & 4/1997-6/2010 & Retrospective, single center & Complicated CTBAD & 71 & 55.1 \\
\hline Shu and colleagues ${ }^{19} 2013$ & $7 / 2003-5 / 2012$ & Retrospective, single center & ATBAD & 127 & 46.1 \\
\hline Mani and colleagues ${ }^{20} 2012$ & $8 / 2000-8 / 2010$ & Retrospective, single center & CTBAD & 58 & 66.0 \\
\hline 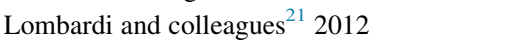 & $12 / 2007-8 / 2009$ & Prospective, multicenter & Complicated TBAD & 40 & 58.0 \\
\hline Andacheh and colleagues ${ }^{22} 2012$ & 2002-2010 & Retrospective, single center & Complicated CTBAD & 73 & 58.0 \\
\hline Steuer and colleagues ${ }^{23} 2011$ & $12 / 1999-12 / 2009$ & Retrospective, single center & Complicated ATBAD & 60 & 67.0 \\
\hline Shu and colleagues ${ }^{24} 2011$ & $7 / 2002-1 / 2009$ & Retrospective, single center & Complicated ATBAD & 45 & 42.6 \\
\hline Kim and colleagues ${ }^{25} 2011$ & $9 / 2002-8 / 2009$ & Retrospective, single center & Complicated ATBAD & 41 & $67.6^{*}$ \\
\hline Kang and colleagues ${ }^{26} 2011$ & 2000-2007 & Retrospective, single center & Complicated CTBAD & 76 & 61.5 \\
\hline $\mathrm{Xu}$ and colleagues ${ }^{27} 2010$ & $6 / 2001-9 / 2007$ & Retrospective, single center & CTBAD & 84 & 53.3 \\
\hline Parsa and colleagues ${ }^{28} 2010$ & $6 / 2005-11 / 2008$ & Retrospective, single center & Complicated TBAD & 55 & 59.0 \\
\hline Zhang and colleagues ${ }^{29} 2015$ & 9/1998-7/2012 & Retrospective, single center & TBAD & 252 & 54.1 \\
\hline VIRTUE $^{30} 2014$ & $12 / 2006-8 / 2009$ & Prospective, multicenter & Complicated TBAD & 100 & 60.7 \\
\hline Nienaber and colleagues ${ }^{31} 2009$ & $11 / 2003-11 / 2005$ & Prospective, multicenter & Complicated TBAD & 72 & 60.3 \\
\hline Total, n (\%) & NA & NA & NA & 2029 & 57.6 \\
\hline
\end{tabular}

$C A D$, Coronary artery disease; $C O P D$, chronic obstructive pulmonary disease; $D M$, diabetes mellitus; $H T N$, hypertension; $R I$, renal insufficiency; $T B A D$, type B aortic dissection; $C T B A D$, chronic type B aortic dissection; $N R$, not reported; $A T B A D$, acute type B aortic dissection; $A D$, aortic dissection; $N A$, not applicable. *Data presented as median.

CI, 8-20) (Figure 3, A) and 17\% (95\% CI, 10-23) (Figure 3, $B)$, respectively. The heterogeneities were still high in the acute and chronic dissection subgroups $(86.4 \%$ and $86.7 \%$, respectively). The phase of dissection was not a source of heterogeneity, because there was an overlap of $95 \%$ CI between the acute and chronic subgroups. The pooled reintervention incidences in the complicated and prior aortic intervention dissection subgroups were 19\% (95\% CI, 14-25) (Figure 4, A) and 22\% (95\% CI, 17-26) (Figure 4, B), respectively. The heterogeneities were $83.2 \%$ and $57.1 \%$, respectively.

The reasons for reintervention after TEVAR are summarized in Table E3. The 3 most common reasons for reintervention were endoleak $(82 / 247,33.2 \%)$, false lumen perfusion and aortic dilation (49/247, 19.8\%), and new dissection $(17 / 247,6.9 \%)$.

The individual effects of several covariates on reintervention are shown in Table 3. We found that the mean age of onset and diabetes mellitus were potential influential factors for reintervention after TEVAR $(P<.001$ and .044 , respectively). The results indicated that advanced age of onset and diabetes mellitus were potential risk and protective factors for reintervention, respectively.

\section{DISCUSSION}

TEVAR has been recognized as a novel and less-invasive alternative to open surgery for treating aortic dissections with a better prognosis. ${ }^{32}$ However, postoperative adverse events such as endoleak, stent-graft migration, and RTAD have undermined the superiorities of TEVAR. In most situations, these life-threatening adverse events must be addressed after evaluating the overall condition of patients. Increasing attention has been paid to reintervention in recent years.

In the present meta-analysis, the pooled overall incidence of reintervention was $15.0 \%$, which was higher than the previously reported rate of $8.1 \%{ }^{4}$ Several factors that resulted in the discrepancy must be considered in this study. First, approximately $15 \%$ of patients underwent prior aortic intervention before endovascular therapy. TEVAR was the secondary intervention for these patients. They were more likely to experience complications and undergo the third 
TABLE 1. Continued

\begin{tabular}{|c|c|c|c|c|c|c|c|}
\hline Male, $n$ & CAD, $n$ & COPD, $\mathbf{n}$ & DM, n & HTN, n & RI, $\mathrm{n}$ & Smoking, $\mathrm{n}$ & Marfan, $\mathbf{n}$ \\
\hline 28 & 18 & 10 & 6 & 41 & 7 & 49 & 0 \\
\hline 23 & 6 & 7 & 9 & 32 & 13 & NR & 4 \\
\hline 154 & 25 & 23 & NR & 187 & 16 & NR & 0 \\
\hline 32 & NR & 9 & 9 & 40 & NR & NR & 0 \\
\hline 29 & 11 & 9 & 3 & 33 & 5 & 2 & 0 \\
\hline 96 & 19 & NR & NR & 114 & NR & NR & 0 \\
\hline 70 & 9 & NR & 4 & 60 & NR & 42 & 1 \\
\hline 14 & 2 & NR & 1 & 20 & 3 & 9 & 0 \\
\hline 17 & 1 & NR & 1 & 18 & NR & 14 & 1 \\
\hline NR & NR & NR & NR & NR & NR & NR & 0 \\
\hline 36 & 9 & 7 & 6 & 46 & 17 & 28 & 4 \\
\hline 34 & 6 & 9 & 2 & 31 & 2 & 18 & 1 \\
\hline 82 & NR & NR & NR & NR & NR & NR & 5 \\
\hline 50 & 2 & NR & 4 & 58 & 3 & 28 & 5 \\
\hline 101 & 32 & NR & 17 & 103 & 26 & 99 & 16 \\
\hline 48 & NR & NR & NR & NR & NR & NR & 0 \\
\hline 28 & $3 / 38$ & $1 / 39$ & 3 & 37 & 2 & $21 / 36$ & 0 \\
\hline 52 & NR & NR & NR & NR & NR & NR & 1 \\
\hline 40 & 12 & NR & 1 & 33 & NR & 25 & 0 \\
\hline 33 & 6 & 6 & 8 & 10 & 7 & NR & 0 \\
\hline 31 & 11 & 7 & 3 & 38 & 6 & 30 & 1 \\
\hline 49 & 29 & 17 & 8 & 75 & 14 & 32 & 2 \\
\hline 69 & NR & NR & 9 & 67 & NR & 26 & 1 \\
\hline 41 & 8 & 9 & 8 & 53 & 21 & 37 & 0 \\
\hline 206 & 9 & 10 & 16 & 193 & 16 & 117 & 0 \\
\hline 76 & 14 & 14 & 1 & 69 & 5 & NR & 0 \\
\hline 62 & NR & 7 & 5 & 61 & NR & 14 & 2 \\
\hline $1501(75.7)$ & $232(14.0)$ & $145(12.7)$ & $124(8.8)$ & $1419(80.9)$ & $163(12.3)$ & $591(50.0)$ & $44(2.2)$ \\
\hline
\end{tabular}

TABLE 2. Perioperative characteristics and crossover/reintervention rate of included studies

\begin{tabular}{|c|c|c|c|c|c|c|c|}
\hline Study reference and year & Patients, $n$ & $\begin{array}{c}\text { Prior aortic } \\
\text { intervention, } \mathbf{n}(\%)\end{array}$ & $\begin{array}{c}\text { In-hospital/30-d } \\
\text { mortality, \% }\end{array}$ & $\begin{array}{c}\text { Mean } \\
\text { follow-up, mo }\end{array}$ & $\begin{array}{c}\text { Reintervention, } \\
\text { n }(\%)\end{array}$ & $\begin{array}{r}\text { Technical } \\
\text { success, \% }\end{array}$ & $\begin{array}{c}\text { Proximal } \\
\text { oversizing, \% }\end{array}$ \\
\hline Wilkinson and colleagues ${ }^{6} 2013$ & 49 & $13(26.5)$ & 10.2 & 27.7 & $5(10.2)$ & 100 & NR \\
\hline Nozdrzykowski and colleagues 2013 & 32 & $6(18.8)$ & 6.3 & 42 & $9(28.1)$ & NR & NR \\
\hline Jia and colleagues $^{8} 2013$ & 208 & NR & 0 & 28.5 & $9(4.3)$ & 100 & $10-20$ \\
\hline Garbade and colleagues $^{9} 2010$ & 46 & NR & 20.0 & 36.9 & $8(17.4)$ & NR & NR \\
\hline $\begin{array}{l}\text { Chemelli-Steingruber and } \\
\text { colleagues }{ }^{10} 2010\end{array}$ & 38 & NR & 13.1 & 33 & $5(13.2)$ & NR & NR \\
\hline Jánosi and colleagues ${ }^{11} 2015$ & 142 & $17(12.0)$ & 4.2 & 47.2 & $29(20.4)$ & NR & 9 \\
\hline Huang and colleagues $^{12} 2015$ & 81 & NR & 6.5 & 12 & $2(2.5)$ & 100 & NR \\
\hline Faure and colleagues ${ }^{13} 2015$ & 24 & $1(4.2)$ & 17.0 & 28 & $8(33.3)$ & 100 & 13.3 \\
\hline Song and colleagues ${ }^{14} 2014$ & 20 & NR & 0 & 10.3 & $2(10.0)$ & 100 & NR \\
\hline Kitamura and colleagues ${ }^{15} 2014$ & 45 & $11(24.4)$ & 0 & 90 & $1 \mathrm{y}: 6(13.3)$ & 100 & NR \\
\hline Hanna and colleagues ${ }^{3} 2014$ & 50 & $11(22.0)$ & 0 & $33.8^{*}$ & $13(26.0)$ & 98 & NR \\
\hline Faure and colleagues ${ }^{16} 2014$ & 41 & $16(39.0)$ & 5.0 & $12.2^{*}$ & $13(31.7)$ & 100 & 14.71 \\
\hline Weng and colleagues ${ }^{17} 2013$ & 99 & NR & NR & $25^{*}$ & $8(8.1)$ & NR & $23 \pm 8$ \\
\hline Lee and colleagues ${ }^{18} 2013$ & 71 & $17(23.9)$ & 1.4 & $49.1^{*}$ & $25(35.2)$ & 97.2 & 10 \\
\hline Shu and colleagues ${ }^{19} 2013$ & 127 & NR & 1.6 & 19.1 & $4(3.1)$ & 100 & $10-15$ \\
\hline Mani and colleagues ${ }^{20} 2012$ & 58 & $12(20.7)$ & 5.2 & 38 & $12 / 47(25.5)$ & NR & $5-15$ \\
\hline Lombardi and colleagues ${ }^{21} 2012$ & 40 & $2(5.0)$ & 5.0 & 12 & $4(10.0)$ & NR & $0-10$ \\
\hline Andacheh and colleagues ${ }^{22} 2012$ & 73 & NR & 14.0 & 18 & $11 / 72(15.3)$ & 99 & NR \\
\hline
\end{tabular}


TABLE 2. Continued

\begin{tabular}{|c|c|c|c|c|c|c|c|}
\hline Study reference and year & Patients, $n$ & $\begin{array}{c}\text { Prior aortic } \\
\text { intervention, } \mathbf{n}(\%)\end{array}$ & $\begin{array}{c}\text { In-hospital/30-d } \\
\text { mortality, \% }\end{array}$ & $\begin{array}{c}\text { Mean } \\
\text { follow-up, mo }\end{array}$ & $\begin{array}{c}\text { Reintervention, } \\
\text { n }(\%)\end{array}$ & $\begin{array}{r}\text { Technical } \\
\text { success, \% }\end{array}$ & $\begin{array}{c}\text { Proximal } \\
\text { oversizing, \% }\end{array}$ \\
\hline Steuer and colleagues $^{23} 2011$ & 60 & NR & 3.3 & 44.4 & $19(31.7)$ & NR & NR \\
\hline Shu and colleagues ${ }^{24} 2011$ & 45 & NR & 4.4 & $13^{*}$ & $1(2.2)$ & 100 & $10-20$ \\
\hline Kim and colleagues ${ }^{25} 2011$ & 41 & NR & 9.8 & $12.4^{*}$ & $9 / 40(22.5)$ & 92.5 & NR \\
\hline Kang and colleagues ${ }^{26} 2011$ & 76 & $29(38.2)$ & 5.0 & 34 & $17(22.4)$ & 96 & $10-15$ \\
\hline $\mathrm{Xu}$ and colleagues ${ }^{27} 2010$ & 84 & NR & 1.2 & 33.2 & $4(4.8)$ & 91.7 & $10-20$ \\
\hline Parsa and colleagues ${ }^{28} 2010$ & 55 & $16(29.1)$ & 2.0 & $7.1 *$ & $13(23.6)$ & 100 & NR \\
\hline Zhang and colleagues $^{29} 2015$ & 252 & 0 & 2.4 & 58.4 & $24(9.5)$ & NR & $14 \pm 2.5$ \\
\hline VIRTUE $2014^{30}$ & 100 & NR & 4.0 & 36 & $22(22.0)$ & 98 & NR \\
\hline Nienaber and colleagues ${ }^{31} 2009$ & 72 & 0 & 2.8 & 24 & $13(18.1)$ & 95.7 & NR \\
\hline Total, n (\%) & 2029 & $151(15.0)$ & 4.3 & 33.7 & 295 (14.6) & 98.3 & NA \\
\hline
\end{tabular}

$N R$, Not reported; $N A$, not applicable. *Data presented as median.

intervention, because the overall condition was inferior to that of patients without prior aortic intervention. The pooled incidence of reintervention in this subgroup was $22 \%$, providing convincing evidence. On the other hand, the incidence of in-hospital/30-day mortality in our study was approximately $4.4 \%$, which was lower than the previous

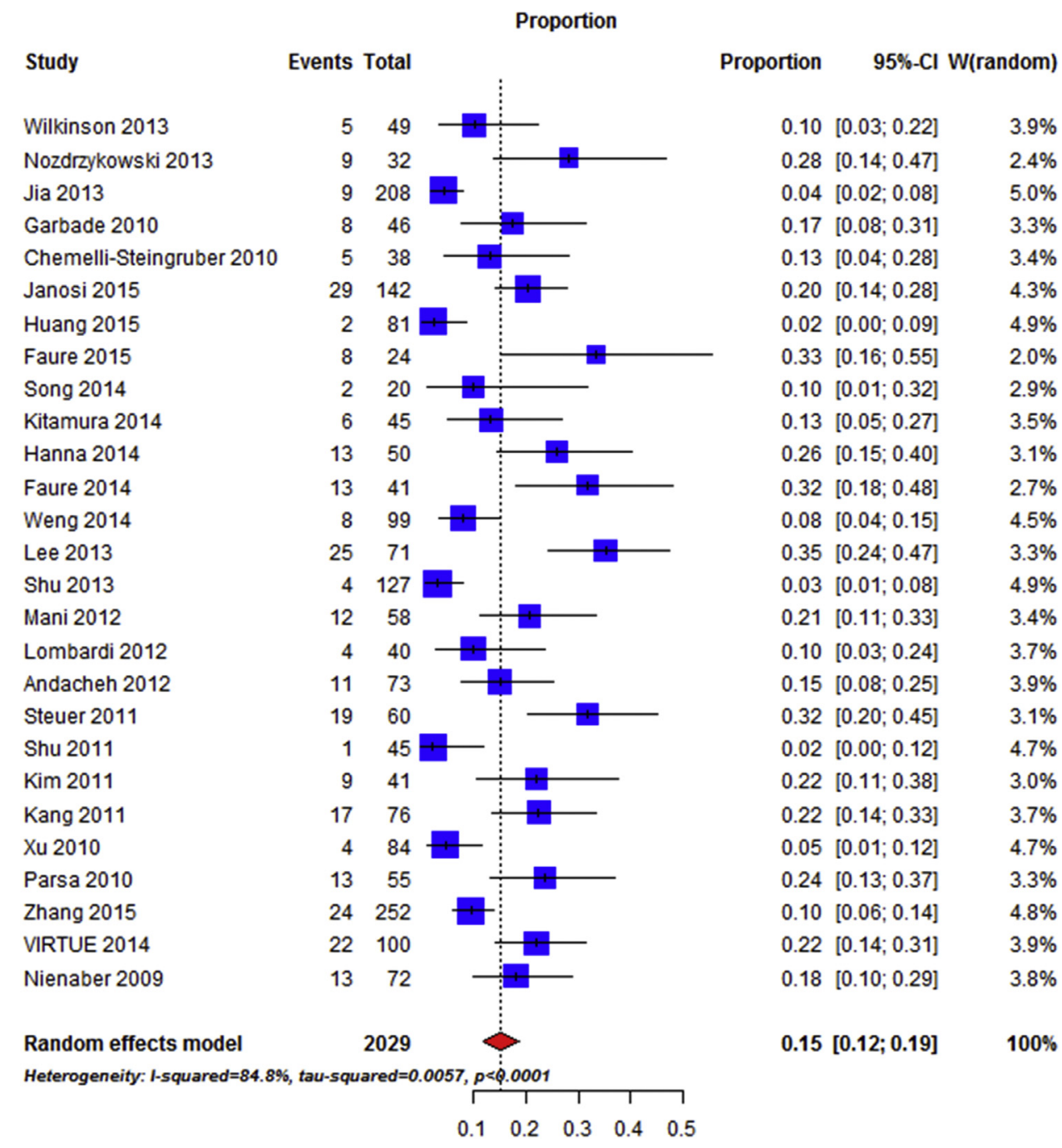

FIGURE 2. Overall incidence of reintervention after TEVAR for aortic dissections. The pooled overall estimate of reintervention incidence after endovascular repair for aortic dissections is shown. $C I$, Confidence interval. 


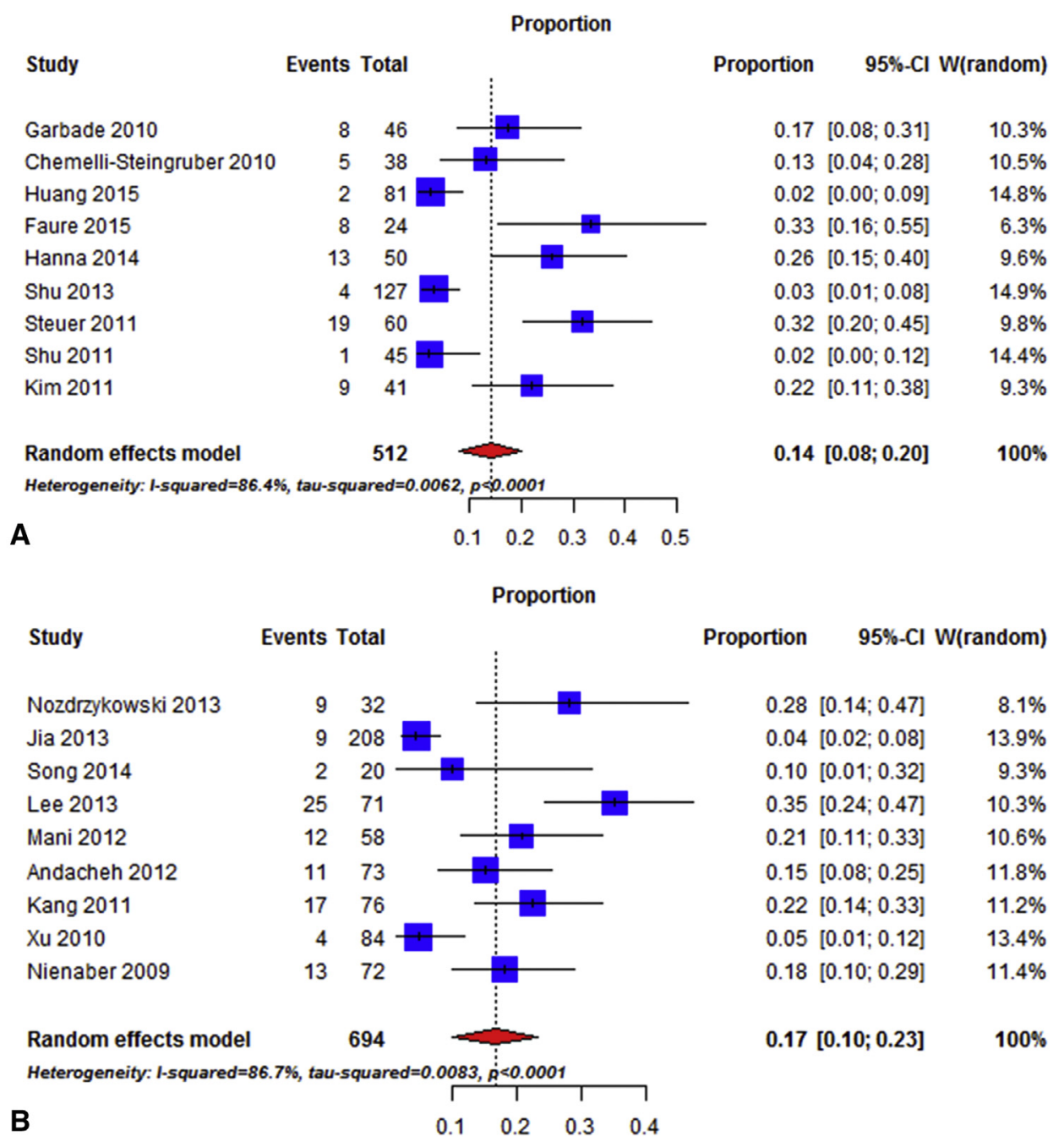

FIGURE 3. Reintervention incidence in acute and chronic dissection subgroups after endovascular repair for aortic dissections. A, Pooled estimate of reintervention incidence in acute dissection subgroup. B, Pooled estimate of reintervention incidence in chronic dissection subgroup. $C I$, Confidence interval.

rate of $5.8 \%{ }^{4}$ It was reasonable that the higher rate of inhospital/30-day mortality, the lower rate of reintervention after TEVAR.

The heterogeneity in the meta-analysis was high, even after sensitivity analysis and subgroup analyses were performed. The results indicated that the heterogeneity might be not relevant to the phase of dissection. This systematic review and meta-analysis included all available studies and evaluated the incidence of reintervention after endovascular repair for aortic dissections. Some confounding factors must be taken into consideration. The time span was from 1995 to April 2013, an approximately 18-year period. Thus, the materials, designs, types, and generations of stent graft might be different. Second, the procedures of TEVAR were performed in different countries, hospitals, and races. Third, the management of the patients was performed by different surgical teams, surgeons, and anesthesiologists, and using different brands of prosthetics.
These confounding factors were inevitable to the nature of the meta-analysis. We still believe our results can be helpful to guide readers to further understand the complex clinical problem.

The rate of technical success was $98.3 \%$. Technical success, defined as a sealing of the primary entry tear without residual endoleak at the end of the procedure, ${ }^{13}$ was an indicator of operator skill and experience. However, technical success was unable to predict the long-term prognosis. It was unsuitable and difficult to determine the relationship between technical success and reintervention during the follow-up period.

The 3 most common reasons for reintervention were endoleak, false lumen perfusion and aortic dilation, and new dissection, which were consistent with the results of a previous retrospective study in our center. ${ }^{29}$ Endoleak, most commonly type I, continues to be a challenge in the endovascular approach for aortic dissections, ${ }^{2}$ especially in 


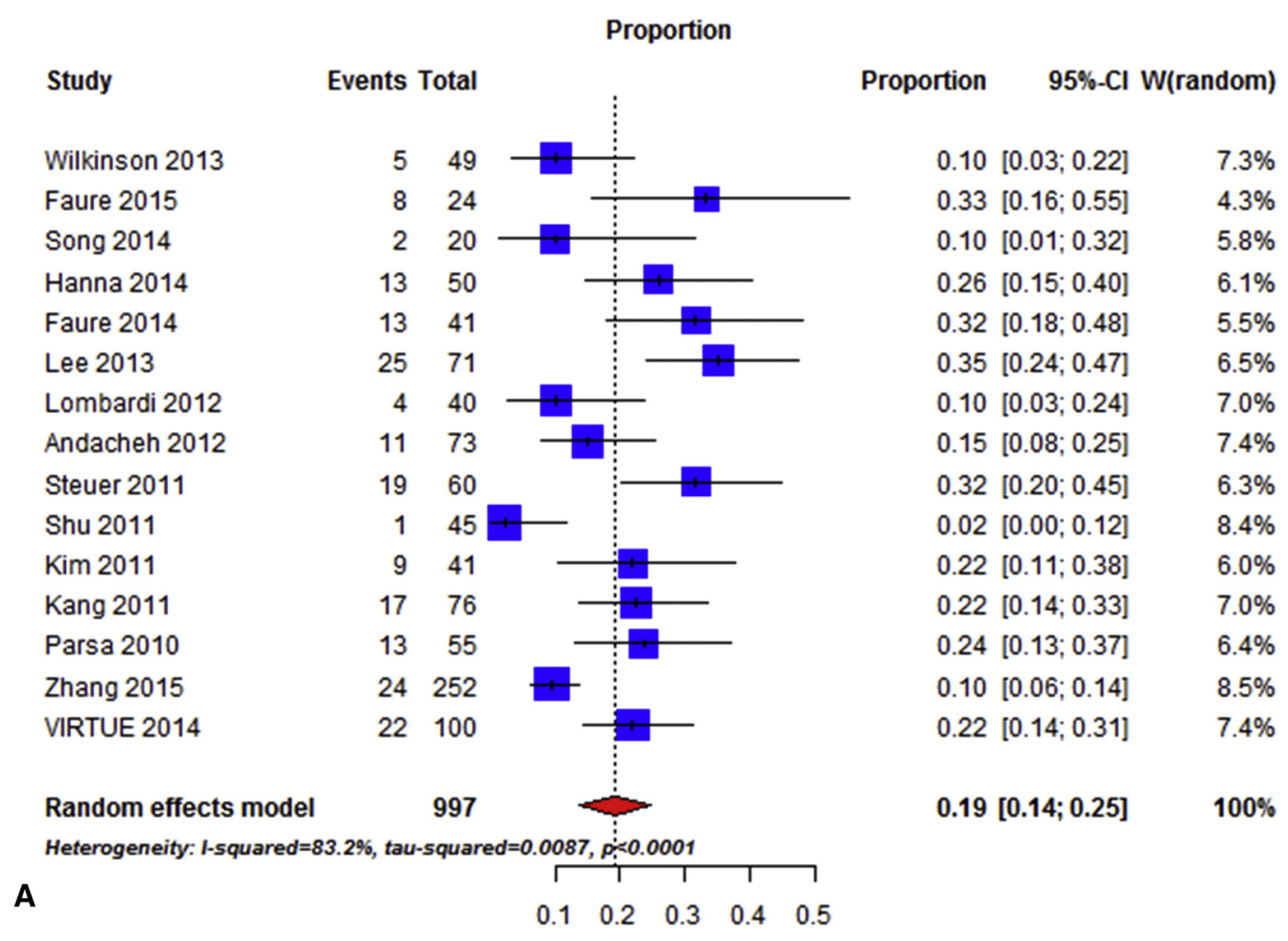

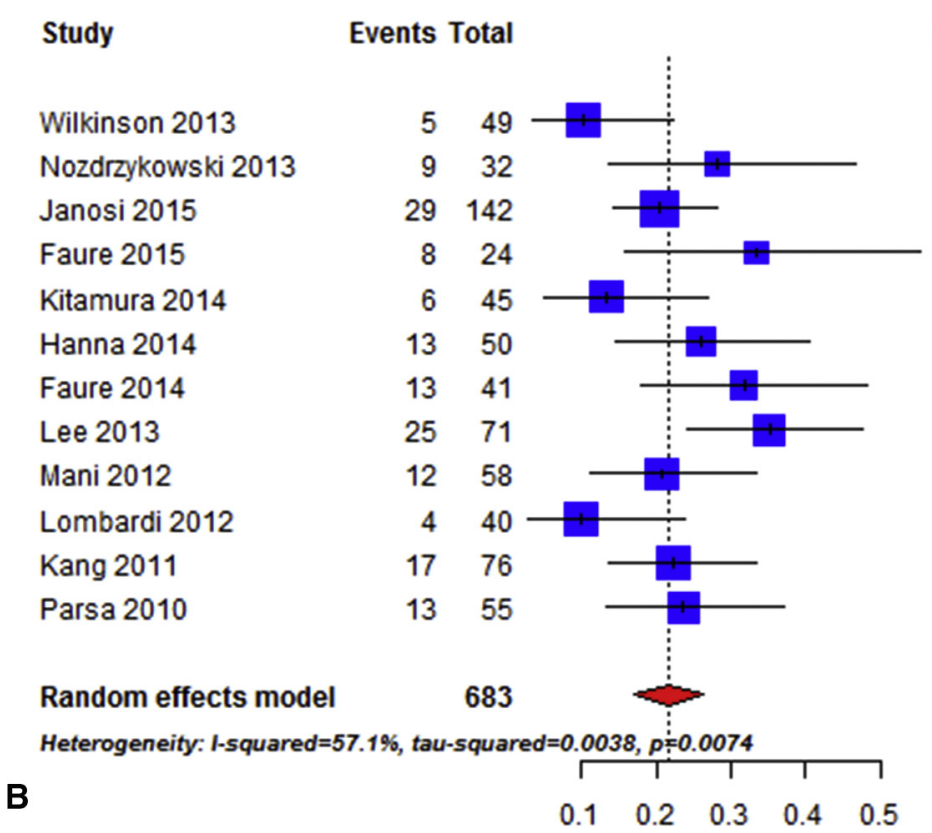

Proportion $\quad 95 \%-\mathrm{Cl}$ W(random)

$\begin{array}{lr}0.10[0.03 ; 0.22] & 10.3 \% \\ 0.28[0.14 ; 0.47] & 5.7 \% \\ 0.20[0.14 ; 0.28] & 11.8 \% \\ 0.33[0.16 ; 0.55] & 4.4 \% \\ 0.13[0.05 ; 0.27] & 9.2 \% \\ 0.26[0.15 ; 0.40] & 7.6 \% \\ 0.32[0.18 ; 0.48] & 6.4 \% \\ 0.35[0.24 ; 0.47] & 8.3 \% \\ 0.21[0.11 ; 0.33] & 8.8 \% \\ 0.10[0.03 ; 0.24] & 9.6 \% \\ 0.22[0.14 ; 0.33] & 9.6 \% \\ 0.24[0.13 ; 0.37] & 8.2 \% \\ & \\ 0.22[0.17 ; 0.26] & 100 \%\end{array}$

FIGURE 4. Reintervention incidence in complicated and prior aortic intervention dissection subgroups after endovascular repair for aortic dissections. A, Pooled estimate of reintervention in the complicated dissection subgroup. B, Pooled estimate of reintervention in the prior aortic intervention dissection subgroup. $C I$, Confidence interval.

patients receiving scallop, fenestration, and chimney techniques. In this study, 82 endoleaks required reintervention. Endoleak would be affected by many factors, such as anatomy of vascular segment, stent-graft design, and short proximal landing zone. ${ }^{33}$ It was mandatory to correct type I endoleak whenever possible because of its association with mean pressure indexes of $93 \%$ in the liquid areas and $62 \%$ in the thrombus. ${ }^{34}$ 
TABLE 3. Individual effect of 13 covariates on reintervention: Results of random effects meta-regression analyses

\begin{tabular}{lcrr}
\hline \multicolumn{1}{c}{ Covariates } & Included studies & Coefficient & $\boldsymbol{P}$ value \\
\hline Mean age of onset, $\mathrm{y}$ & 27 & 0.0090 & $<.001$ \\
Male, n & 26 & -0.0008 & .057 \\
Coronary artery disease, $\mathrm{n}$ & 20 & -0.0037 & .198 \\
Chronic obstructive & 15 & -0.0022 & .631 \\
$\quad$ pulmonary disease, $\mathrm{n}$ & & & \\
Diabetes mellitus, n & 21 & -0.0101 & .044 \\
Hypertension, n & 23 & -0.0006 & .158 \\
Renal insufficiency, n & 16 & -0.0050 & .193 \\
Smoking, n & 17 & -0.0015 & .089 \\
Marfan syndrome, n & 27 & -0.0040 & .475 \\
Prior aortic intervention, n & 14 & 0.0041 & .144 \\
Technical success, \% & 18 & -0.0053 & .601 \\
In hospital/30-d mortality, \% & 26 & 0.0026 & .510 \\
Mean follow-up period, mo & 27 & 0.0012 & .274 \\
\hline
\end{tabular}

The other common reason for reintervention was persistent perfusion of the false lumen and aortic dilation, which result in partial or incomplete thrombosis of the false lumen. Tsai and colleagues ${ }^{35}$ concluded that partial thrombosis of the false lumen was an important determinant of aortic enlargement and a significant independent predictor of postdischarge mortality. We considered that partial thrombosis occluded the distal reentry tears and resulted in turbulence and a blind sac, which would significantly increase mean arterial and diastolic pressures.

RTAD was an uncommon but a devastating complication in endovascular treatment for type B dissections, especially for arch dissection using the hybrid method. ${ }^{36}$ In the present study, the incidence of RTAD was $0.92 \%$ (16/1742), which was approximately one half that in the study by Canaud and colleagues, ${ }^{37}$ who demonstrated that excessive oversizing of the proximal stent graft was a risk factor of RTAD. The device oversizing increased per $1 \%$, and the incidence of RTAD increased per $9 \%$. Moreover, the incidence of RTAD was not associated with the proximal endograft configuration. $^{37}$ At present, the optimal oversizing for type B aortic dissection remains controversial. Previous studies reported that excessive oversizing was a potential risk factor for reintervention after TEVAR. ${ }^{16,29}$ However, many of the included studies reported the range of oversizing, 8,19-21,24,26,27 except the studies reporting the mean ${ }^{11,17,18,29}$ or median. ${ }^{13,16}$ Although the potential relationship between oversizing and reintervention could not be explored, the selection of oversizing is important. It is important to highlight that an accurate preoperative measurement of the proximal aorta at the transection of the intended landing zone was essential to determine the oversizing.

Our results showed that advanced age of onset was a potential risk factor for reintervention. To our surprise, however, diabetes mellitus was a protective factor for reintervention. A recent published meta-analysis also suggested that diabetes mellitus may be negatively associated with the presence of thoracic aortic dissection and aneurysm. ${ }^{38}$ Theivacumar and colleagues ${ }^{39}$ suggested that diabetes mellitus has a protective effect against aortic dissection. The possible mechanism that diabetes mellitus protected the patients from reintervention should be explored further.

\section{Study Limitations}

First, the analysis was composed of only 2403 patients with aortic dissection, which was a relatively small sample for a meta-analysis. However, it should be noted that the number of 27 included studies was more important than the number of patients. Second, the fact that approximately $15.0 \%$ of patients underwent prior aortic intervention might cause selection bias. Third, many confounding factors, such as stent-graft brands, types, and generations, length of stentgraft coverage, anesthesia method, and distal reentry tear management, could not be eliminated, because this information was unavailable from most of the included studies. Fourth, the heterogeneity was high, even after sensitivity analysis and subgroup analyses were performed. Nonetheless, the study helps to clarify the true incidence of reintervention after TEVAR and sheds light on the subject.

\section{CONCLUSIONS}

Overall, the existing evidence suggests that the incidence of reintervention after TEVAR is relatively high during midterm follow-up. The 3 most common reasons for reintervention are endoleak, false lumen perfusion and aortic dilation, and new dissection. A risk factor of reintervention after TEVAR is advanced age of onset. Diabetes mellitus is a potential protective factor of reintervention. Although it remains an important caveat that these conclusions are based on retrospective studies, the study confirming some of the major findings of previous analyses increases confidence that the results are robust.

\section{Conflict of Interest Statement}

Authors have nothing to disclose with regard to commercial support.

The authors thank Tianyi Zhang, MD, and Qi Chen, MD, Department of Health Statistics, Second Military Medical University, Shanghai, China, for valuable guidance on methodology.

\section{References}

1. Olsson C, Thelin S, Stahle E, Ekbom A, Granath F. Thoracic aortic aneurysm and dissection: increasing prevalence and improved outcomes reported in a nationwide population-based study of more than 14,000 cases from 1987 to 2002. Circulation. 2006;114:2611-8

2. Patterson B, Holt P, Nienaber C, Cambria R, Fairman R, Thompson M. Aortic pathology determines midterm outcome after endovascular repair of the thoracic aorta: report from the Medtronic Thoracic Endovascular Registry (MOTHER) database. Circulation. 2013;127:24-32. 
3. Hanna JM, Andersen ND, Ganapathi AM, McCann RL, Hughes GC. Five-year results for endovascular repair of acute complicated type B aortic dissection. J Vasc Surg. 2014;59:96-106.

4. Cheng D, Martin J, Shennib H, Dunning J, Muneretto C, Schueler S, et al. Endovascular aortic repair versus open surgical repair for descending thoracic aortic disease a systematic review and meta-analysis of comparative studies. J Am Coll Cardiol. 2010;55:986-1001.

5. Liberati A, Altman DG, Tetzlaff J, Mulrow C, Gøtzsche PC, Ioannidis JP, et al. The PRISMA statement for reporting systematic reviews and meta-analyses of studies that evaluate health care interventions: explanation and elaboration. PLoS Med. 2009;6:e1000100.

6. Wilkinson DA, Patel HJ, Williams DM, Dasika NL, Deeb GM. Early open and endovascular thoracic aortic repair for complicated type B aortic dissection. Ann Thorac Surg. 2013;96:23-30.

7. Nozdrzykowski M, Etz CD, Luehr M, Garbade J, Misfeld M, Borger MA, et al. Optimal treatment for patients with chronic Stanford type B aortic dissection: endovascularly, surgically or both? Eur J Cardiothorac Surg. 2013;44:e165-74.

8. Jia X, Guo W, Li TX, Guan S, Yang RM, Liu XP, et al. The results of stent graft versus medication therapy for chronic type B dissection. J Vasc Surg. 2013;57: 406-14.

9. Garbade J, Jenniches M, Borger MA, Barten MJ, Scheinert D, Gutberlet M, et al. Outcome of patients suffering from acute type B aortic dissection: a retrospective single-centre analysis of 135 consecutive patients. Eur J Cardiothorac Surg. 2010;38:285-92.

10. Chemelli-Steingruber I, Chemelli A, Strasak A, Hugl B, Hiemetzberger R, Jaschke W, et al. Endovascular repair or medical treatment of acute type B aortic dissection? A comparison. Eur J Radiol. 2010;73:175-80.

11. Jánosi RA, Tsagakis K, Bettin M, Kahlert P, Horacek M, Al-Rashid F, et al. Thoracic aortic aneurysm expansion due to late distal stent graft-induced new entry. Catheter Cardiovasc Interv. 2015;85:E43-53.

12. Huang W, Yang F, Luo J, Xie N, He P, Luo S, et al. Outcomes and morphologic changes of immediate type IA endoleak following endovascular repair of acute type B aortic dissection. Ann Vasc Surg. 2015;29:174-82.

13. Faure EM, Canaud L, Marty-Ane C, Becquemin JP, Alric P. Endovascular management of rupture in acute type B aortic dissections. Eur J Vasc Endovasc Surg. 2015;49:655-60.

14. Song SW, Kim TH, Lim SH, Lee KH, Yoo KJ, Cho BK. Prognostic factors for aorta remodeling after thoracic endovascular aortic repair of complicated chronic DeBakey IIIb aneurysms. J Thorac Cardiovasc Surg. 2014;148:925-32.

15. Kitamura T, Torii S, Oka N, Horai T, Nakashima K, Itatani K, et al. Key success factors for thoracic endovascular aortic repair for non-acute Stanford type B aortic dissection. Eur J Cardiothorac Surg. 2014;46:432-7.

16. Faure EM, Canaud L, Agostini C, Shaub R, Böge G, Marty-ané C, et al. Reintervention after thoracic endovascular aortic repair of complicated aortic dissection. J Vasc Surg. 2014;59:327-33.

17. Weng SH, Weng CF, Chen WY, Huang CY, Chen IM, Chen CK, et al. Reintervention for distal stent graft-induced new entry after endovascular repair with a stainless steel-based device in aortic dissection. J Vasc Surg. 2013;57:64-71.

18. Lee M, Lee do Y, Kim MD, Lee MS, Won JY, Park SI, et al. Outcomes of endovascular management for complicated chronic type B aortic dissection: effect of the extent of stent graft coverage and anatomic properties of aortic dissection. J Vasc Interv Radiol. 2013;24:1451-60.

19. Shu C, Fang K, Luo M, Li Q, Wang Z. Emergency endovascular stent-grafting for acute type B aortic dissection with symptomatic malperfusion. Int Angiol. 2013; 32:483-91.

20. Mani K, Clough RE, Lyons OT, Bell RE, Carrell TW, Zayed HA, et al. Predictors of outcome after endovascular repair for chronic type B dissection. Eur J Vasc Endovasc Surg. 2012;43:386-91.

21. Lombardi JV, Cambria RP, Nienaber CA, Chiesa R, Teebken O, Lee A, et al. Prospective multicenter clinical trial (STABLE) on the endovascular treatment of complicated type B aortic dissection using a composite device design. J Vasc Surg. 2012;55:629-40.e2.
22. Andacheh ID, Donayre C, Othman F, Walot I, Kopchok G, White R. Patient outcomes and thoracic aortic volume and morphologic changes following thoracic endovascular aortic repair in patients with complicated chronic type B aortic dissection. J Vasc Surg. 2012;56:644-50.

23. Steuer J, Eriksson MO, Nyman R, Bjorck M, Wanhainen A. Early and long-term outcome after thoracic endovascular aortic repair (TEVAR) for acute complicated type B aortic dissection. Eur J Vasc Endovasc Surg. 2011;41:318-23.

24. Shu C, He H, Li QM, Li M, Jiang XH, Luo MY. Endovascular repair of complicated acute type-B aortic dissection with stentgraft: early and mid-term results. Eur J Vasc Endovasc Surg. 2011;42:448-53.

25. Kim KM, Donayre CE, Reynolds TS, Kopchok GE, Walot I, Chauvapun JP, et al. Aortic remodeling, volumetric analysis, and clinical outcomes of endoluminal exclusion of acute complicated type B thoracic aortic dissections. J Vasc Surg. 2011;54:316-24.

26. Kang WC, Greenberg RK, Mastracci TM, Eagleton MJ, Hernandez AV, Pujara AC, et al. Endovascular repair of complicated chronic distal aortic dissections: intermediate outcomes and complications. J Thorac Cardiovasc Surg. 2011;142:1074-83.

27. Xu SD, Huang FJ, Yang JF, Li ZZ, Yang S, Du JH, et al. Early and midterm results of thoracic endovascular aortic repair of chronic type B aortic dissection. J Thorac Cardiovasc Surg. 2010;139:1548-53.

28. Parsa CJ, Schroder JN, Daneshmand MA, McCann RL, Hughes GC. Midterm results for endovascular repair of complicated acute and chronic type B aortic dissection. Ann Thorac Surg. 2010;89:97-104.

29. Zhang L, Zhou J, Lu Q, Zhao Z, Bao J, Jing Z. Potential risk factors of reintervention after endovascular repair for type B aortic dissections. Catheter Cardiovasc Interv. 2015;86:E1-10.

30. VIRTUE Registry Investigators. Mid-term outcomes and aortic remodelling after thoracic endovascular repair for acute, subacute, and chronic aortic dissection: the VIRTUE Registry. Eur J Vasc Endovasc Surg. 2014;48:363-71.

31. Nienaber CA, Rousseau H, Eggebrecht H, Kische S, Fattori R, Rehders TC, et al. Randomized comparison of strategies for type B aortic dissection: the Investigation of STEnt Grafts in Aortic Dissection (INSTEAD) trial. Circulation. 2009; 120:2519-28.

32. Schaffer JM, Lingala B, Miller DC, Woo YJ, Mitchell RS, Dake MD. Midterm survival after thoracic endovascular aortic repair in more than 10,000 Medicare patients. J Thorac Cardiovasc Surg. 2015;149:808-20.

33. Boufi M, Aouini F, Guivier-Curien C, Dona B, Loundou AD, Deplano V, et al. Examination of factors in type I endoleak development after thoracic endovascular repair. J Vasc Surg. 2015;61:317-23.

34. Rosen RJ, Green RM. Endoleak management following endovascular aneurysm repair. J Vasc Interv Radiol. 2008;19:S37-43.

35. Tsai TT, Evangelista A, Nienaber CA, Myrmel T, Meinhardt G, Cooper JV, et al. Partial thrombosis of the false lumen in patients with acute type B aortic dissection. N Engl J Med. 2007;357:349-59.

36. Gandet T, Canaud L, Ozdemir BA, Ziza V, Demaria R, Albat B, et al. Factors favoring retrograde aortic dissection after endovascular aortic arch repair. J Thorac Cardiovasc Surg. 2015;150:136-42.

37. Canaud L, Ozdemir BA, Patterson BO, Holt PJ, Loftus IM, Thompson MM. Retrograde aortic dissection after thoracic endovascular aortic repair. Ann Surg. 2014;260:389-95.

38. Takagi H, Umemoto T, ALICE (All-Literature Investigation of Cardiovascular Evidence) Group. Negative association of diabetes with thoracic aortic dissection and aneurysm. Angiology. 2016 [Epub ahead of print].

39. Theivacumar NS, Stephenson MA, Mistry H, Valenti D. Diabetics are less likely to develop thoracic aortic dissection: a 10-year single-center analysis. Ann Vasc Surg. 2014;28:427-32.

Key Words: aortic dissection, reintervention, endovascular repair 


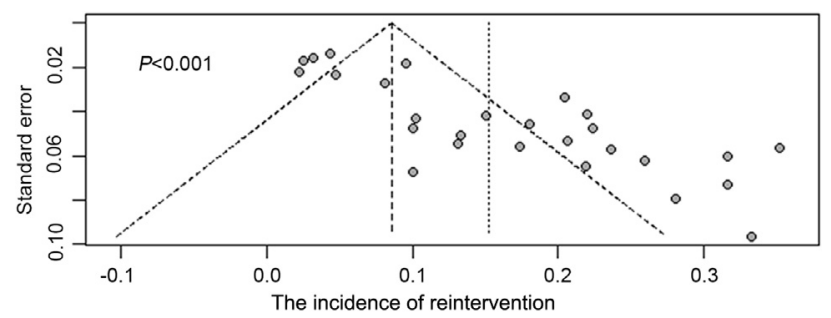

FIGURE E1. Funnel plot of all included studies for reintervention. Publication bias of pooled overall incidence of reintervention was assessed by funnel plot. Each point represents a study, and publication bias exists.

TABLE E1. Search strategies in PubMed and Embase databases (June 2, 2015)

\begin{tabular}{|c|c|c|c|}
\hline Search & Query & Items found & Time \\
\hline \multicolumn{4}{|l|}{ PubMed } \\
\hline \#3 & Search\#1 AND\#3 Filters: Humans; English & 120 & 23:28:00 \\
\hline$\# 2$ & $\begin{array}{l}\text { Search ((reintervention*[Title/Abstract]) OR secondary intervention*[Title/Abstract]) OR re-intervention* } \\
\text { [Title/Abstract] Filters: Humans; English }\end{array}$ & 4604 & 23:27:19 \\
\hline$\# 1$ & Search (TEVAR[Title/Abstract]) OR thoracic endovascular aortic repair[Title/Abstract] Filters: Humans; English & 728 & $23: 26: 29$ \\
\hline \multicolumn{4}{|l|}{ Embase } \\
\hline \#3 & \#1 AND\#2 & 170 & - \\
\hline$\# 2$ & $\begin{array}{l}\text { reintervention:ab,ti OR ‘secondary intervention':ab,ti OR 're intervention':ab,ti AND [english]/lim AND } \\
\text { [humans]/lim AND [embase]/lim }\end{array}$ & 5563 & - \\
\hline$\# 1$ & tevar:ab,ti OR 'thoracic endovascular aortic repair':ab,ti AND [english]/lim AND [humans]/lim AND [embase]/lim & 1125 & - \\
\hline
\end{tabular}

TEVAR, Thoracic endovascular aortic repair. 
TABLE E2. Sensitivity analysis of included studies using random effect model

\begin{tabular}{|c|c|c|c|c|}
\hline Omitting study & Proportion & $95 \% \mathrm{CI}$ & Tau $^{2}$ & $\mathbf{I}^{2} \%$ \\
\hline Wilkinson and colleagues ${ }^{6} 2013$ & 0.1553 & $0.1207-0.1899$ & 0.0059 & 85.4 \\
\hline Nozdrzykowski and colleagues ${ }^{7} 2013$ & 0.1493 & $0.1157-0.1829$ & 0.0055 & 84.9 \\
\hline Jia and colleagues $^{8} 2013$ & 0.1599 & $0.1239-0.1960$ & 0.0065 & 84.4 \\
\hline Garbade and colleagues ${ }^{9} 2010$ & 0.1522 & $0.1180-0.1863$ & 0.0057 & 85.2 \\
\hline Chemelli-Steingruber and colleagues ${ }^{10} 2010$ & 0.1538 & $0.1195-0.1881$ & 0.0058 & 85.4 \\
\hline Jánosi and colleagues ${ }^{11} 2015$ & 0.1500 & $0.1163-0.1837$ & 0.0055 & 84.2 \\
\hline Huang and colleagues ${ }^{12} 2015$ & 0.1599 & 0.1249-0.1949 & 0.006 & 84.1 \\
\hline Faure and colleagues ${ }^{13} 2015$ & 0.1489 & $0.1154-0.1823$ & 0.0055 & 84.8 \\
\hline Song and colleagues ${ }^{14} 2014$ & 0.1546 & 0.1204-0.1889 & 0.0058 & 85.4 \\
\hline Kitamura and colleagues ${ }^{15} 2014$ & 0.1538 & 0.1194-0.1882 & 0.0058 & 85.3 \\
\hline Hanna and colleagues ${ }^{3} 2014$ & 0.1490 & $0.1154-0.1826$ & 0.0055 & 84.7 \\
\hline Faure and colleagues ${ }^{16} 2014$ & 0.1477 & $0.1144-0.1810$ & 0.0054 & 84.5 \\
\hline Weng and colleagues ${ }^{17} 2014$ & 0.1570 & $0.1219-0.1922$ & 0.0061 & 85.4 \\
\hline Lee and colleagues ${ }^{18} 2013$ & 0.1444 & $0.1121-0.1767$ & 0.0049 & 83.2 \\
\hline Shu and colleagues ${ }^{19} 2013$ & 0.1599 & $0.1246-0.1953$ & 0.0061 & 84.1 \\
\hline Mani and colleagues ${ }^{20} 2012$ & 0.1508 & $0.1168-0.1847$ & 0.0056 & 84.9 \\
\hline Lombardi and colleagues ${ }^{21} 2012$ & 0.1552 & $0.1207-0.1897$ & 0.0059 & 85.4 \\
\hline Andacheh and colleagues ${ }^{22} 2012$ & 0.1531 & $0.1187-0.1875$ & 0.0058 & 85.2 \\
\hline Steuer and colleagues ${ }^{23} 2011$ & 0.1465 & $0.1135-0.1795$ & 0.0052 & 84.0 \\
\hline Shu and colleagues ${ }^{24} 2011$ & 0.1597 & $0.1249-0.1945$ & 0.0059 & 84.6 \\
\hline Kim and colleagues ${ }^{25} 2011$ & 0.1507 & $0.1168-0.1846$ & 0.0056 & 85.0 \\
\hline Kang and colleagues ${ }^{26} 2011$ & 0.1497 & $0.1160-0.1835$ & 0.0055 & 84.7 \\
\hline $\mathrm{Xu}$ and colleagues ${ }^{27} 2010$ & 0.1588 & $0.1236-0.1940$ & 0.0061 & 85.2 \\
\hline Parsa and colleagues ${ }^{28} 2010$ & 0.1497 & $0.1160-0.1834$ & 0.0055 & 84.8 \\
\hline Zhang and colleagues $^{29} 2015$ & 0.1572 & $0.1212-0.1933$ & 0.0065 & 85.4 \\
\hline VIRTUE $2014^{30}$ & 0.1495 & $0.1159-0.1832$ & 0.0055 & 84.4 \\
\hline Nienaber and colleagues ${ }^{31} 2009$ & 0.1517 & $0.1176-0.1859$ & 0.0057 & 85.0 \\
\hline Pooled estimate & 0.1529 & $0.1193-0.1864$ & 0.0057 & 84.8 \\
\hline
\end{tabular}

CI, Confidence interval. 
TABLE E3. Reasons for reintervention after endovascular repair for aortic dissections

\begin{tabular}{|c|c|c|}
\hline Study & Patients, $n$ & Total number: Reintervention causes \\
\hline Wilkinson and colleagues $^{6} 2013$ & 49 & 5: 2 AAA; 3 Type I endoleak \\
\hline Nozdrzykowski and colleagues ${ }^{7} 2013$ & 32 & 9: 2 Distal-organ malperfusion; 7 Stent-graft migration \\
\hline Jia and colleagues ${ }^{8} 2013$ & 208 & 9: 3 Endoleak; 6 Distal aorta rupture \\
\hline Garbade and colleagues $^{9} 2010$ & 46 & $\mathrm{NR}$ \\
\hline Chemelli-Steingruber and colleagues ${ }^{10} 2010$ & 38 & 5: 2 Type III endoleak; 3 RTAD \\
\hline Jánosi and colleagues ${ }^{11} 2015$ & 142 & $\mathrm{NR}$ \\
\hline Huang and colleagues ${ }^{12} 2015$ & 81 & 2: 2 Type I endoleak \\
\hline Faure and colleagues ${ }^{13} 2015$ & 24 & $\begin{array}{l}\text { 8: } 4 \text { Type I endoleak; } 1 \text { Type II endoleak; } 1 \text { Stent-graft migration; } 1 \text { New dissection; } 1 \text { New } \\
\text { aneurysm }\end{array}$ \\
\hline Song and colleagues ${ }^{14} 2014$ & 20 & 2: 2 New dissection \\
\hline Kitamura and colleagues ${ }^{15} 2014$ & 45 & NR \\
\hline Hanna and colleagues ${ }^{3} 2014$ & 50 & $\begin{array}{l}\text { 13: } 4 \text { Type I endoleak; } 3 \text { Metachronous aortic pathology separate from the initially treated } \\
\text { dissection; } 3 \text { False lumen dilation; } 2 \text { Type II endoleak; } 1 \text { RTAD }\end{array}$ \\
\hline Faure and colleagues ${ }^{16} 2014$ & 41 & 13: 2 Stent-graft migration; 7 Type I endoleak 1 Type II endoleak; 3 Aneurysm evolution \\
\hline Weng and colleagues ${ }^{17} 2013$ & 99 & 8: 8 Stent-graft-induced new dissection \\
\hline Lee and colleagues ${ }^{18} 2013$ & 71 & $\begin{array}{l}27 \text { (25 patients): } 1 \text { Iatrogenic dissection; } 2 \text { Spontaneous dissection; } 1 \text { Extension of } \\
\text { dissection; } 9 \text { Type I endoleak; } 11 \text { Enlargement of dissection; } 2 \text { Rupture of dissection; } 1 \\
\text { True lumen collapse }\end{array}$ \\
\hline Shu and colleagues ${ }^{19} 2013$ & 127 & 4: 3 Perfusion of false lumen; 1 Right renal artery compressed \\
\hline Mani and colleagues ${ }^{20} 2012$ & 58 & $\mathrm{NR}$ \\
\hline Lombardi and colleagues ${ }^{21} 2012$ & 40 & $\begin{array}{l}\text { 4: } 1 \text { Liver and gall bladder ischemia; } 1 \text { Renal failure; } 1 \text { Retrograde dissection; } 1 \text { Stent-graft } \\
\text { migration }\end{array}$ \\
\hline Andacheh and colleagues ${ }^{22} 2012$ & 73 & 11: 7 Endoleak; 4 Persistent distal perfusion of false lumen \\
\hline Steuer and colleagues ${ }^{23} 2011$ & 60 & $\begin{array}{l}\text { 19: } 10 \text { Aortic dilation; } 2 \text { Left arm claudication; } 1 \text { Left arm rest pain; } 1 \text { Subclavian steal } \\
\text { syndrome; } 2 \text { Type II endoleak; } 1 \text { Aneurysm; } 2 \text { Stenting of the left renal artery }\end{array}$ \\
\hline Shu and colleagues ${ }^{24} 2011$ & 45 & 1: 1 Type I endoleak \\
\hline Kim and colleagues ${ }^{25} 2011$ & 41 & 12 (9 patients): 7 Type I endoleak; 3 Distal reperfusion; 2 RTAD \\
\hline Kang and colleagues ${ }^{26} 2011$ & 76 & $\begin{array}{l}\text { 19: } 3 \text { RTAD; } 10 \text { Aortic enlargement; } 2 \text { Type I endoleak; } 1 \text { Type II endoleak; } 3 \text { Stent-graft } \\
\text { and true lumen collapse }\end{array}$ \\
\hline $\mathrm{Xu}$ and colleagues ${ }^{27} 2010$ & 84 & 4: 3 Endoleak; 1 RTAD \\
\hline Parsa and colleagues ${ }^{28} 2010$ & 55 & $\begin{array}{l}\text { 13: } 1 \text { LCCA coverage; } 1 \text { Iliac arterial rupture; } 1 \text { Stent-graft migration; } 1 \text { LCCA dissection; } \\
\text { 1 Aortic dilation; } 1 \text { Aortoesophageal fistula; } 2 \text { Stent-graft collapse; } 3 \text { False lumen } \\
\text { dilation; } 2 \text { Metachronous aortic pathology }\end{array}$ \\
\hline Zhang and colleagues ${ }^{29} 2015$ & 252 & $\begin{array}{l}\text { 24: } 3 \text { Type I endoleak; } 2 \text { Type II endoleak; } 5 \text { New dissection; } 4 \text { New aneurysm; } 5 \text { False } \\
\text { lumen dilation; } 2 \text { RTAD; } 2 \text { Redissection; } 1 \text { Right iliac artery occlusion }\end{array}$ \\
\hline VIRTUE $2014^{30}$ & 100 & 22: 15 Type I endoleak; 1 Type III endoleak; 2 Aortic rupture; 2 RTAD; 2 Others \\
\hline Nienaber and colleagues ${ }^{31} 2009$ & 72 & 13: 7 False-lumen flow and diameter expansion; 1 RTAD; 1 Malperfusion; 4 Others \\
\hline Total, $\mathrm{n}$ & 2029 & $\begin{array}{l}\text { 247: } 82 \text { Endoleak; } 49 \text { False lumen perfusion and aortic dilation; } 17 \text { New dissection; } 16 \\
\text { RTAD; } 14 \text { Organ malperfusion; } 12 \text { Stent-graft migration; } 11 \text { Enlargement of dissection; } \\
\text { 10 Aortic rupture; } 8 \text { Stent-graft induced new dissection; } 6 \text { New aneurysm; } 6 \text { True lumen } \\
\text { collapse; } 5 \text { AAA; } 3 \text { Redissection; } 1 \text { Aortoesophageal fistula; } 1 \text { Iliac arterial rupture; } 6 \\
\text { Others }\end{array}$ \\
\hline
\end{tabular}

$A A A$, Abdominal aortic aneurysm; $N R$, not reported; RTAD, retrograde type A aortic dissection; $L C C A$, left common carotid artery 